\title{
Gövde Borulu Isı Değiştiricilerinde Farklı Tip Şaşırtma Levhalarının Isı ve Akış Analizi
}

\author{
Tuğçe KARATAŞ*, İshak Gökhan AKSOY \\ İn̈nü Üniversitesi, Mühendislik Fakültesi, Makine Mühendisliği Bölümü, Malatya, Türkiye \\ (ORCID: 0000-0001-5261-714X)(ORCID: 0000-0002-8798-5847)
}

\begin{abstract}
$\ddot{O} z$
Gövde - boru tipi 1sı değiştirici tasarımları hem analitik yöntemlerle hem de hesaplamalı akışkanlar dinamiği (HAD) yazılımları ile sayısal olarak yapılabilmektedir. Bu çalışmada model olarak kü̧̈ük boyutlardaki gövde boru tipi bir 1sı değiştirici tasarlanmıştır. Modellemede bir gövde, bir boru geçişli gövde - boru tipi 1sı değiştirici kullanılmıştır. Yapılan çalışmada gövde içindeki boruların yüzey sıcaklığı sabit kabul edilmiş, sadece gövde tarafı akış analizi gerçekleştirilerek, 1sı taşınım katsayısı ve akış özellikleri incelenmiştir. Farklı şaşırtma levha tipleri, akış hızları, türbülans modelleri, ağ boyutları kullanılarak gövde tarafı basınç düşümleri ve ısı taşınım katsayıları için ANSYS Fluent programında HAD analizleri yapılmışı̧ı. Tek parçalı şaşırtma levhaları için elde edilen sayısal sonuçlar Kern analitik yönteminden elde edilen sonuçlarla karşılaştırılmışır. Tek parçalı, disk ve halka şeklindeki şaşırtma levhası kullanılan gövde - boru tipi 1sı değiştiricisinin 1S1 taşınım katsayısı ve basınç düşümü incelenmiştir. A $\breve{g}$ yapısının ısı transferine olan etkisi incelenip sıkı ă̆ yapısının daha iyi sonuçlar verdiği görülmüş̧ür. Türbülans modellerinin karşılaştırılmaları yapılıp daha iyi sonuç veren $\boldsymbol{k}-\boldsymbol{\varepsilon}$ türbülans modeli diğer analizlerde kullanılmıştır.
\end{abstract}

Anahtar kelimeler: Gövde - boru tipi ısı değiştirici, hesaplamalı akışkanlar dinamiği (HAD), tek parçalı, disk ve halka şaşırtma levhası

\section{Heat and Flow Analysis of Different Type Baffle in Shell and Tube Heat Exchanger}

\begin{abstract}
Shell - tube heat exchanger designs can be performed both analytical methods and numerical methods by using the computational fluid dynamics (CFD) software. In this study, a small size shell - tube type heat exchanger was designed as a model. In the modelling, shell and tube heat exchanger with one shell pass and one tube pass was used. In the performed study, the surface temperature of the tubes in the shell was assumed to be constant, only shell side flow analysis was performed and shell side heat transfer coefficient and flow properties were investigated. CFD analysis were performed by using ANSYS Fluent to determine the pressure drop and heat transfer coefficient by using different flow velocity values, turbulence models, mesh, baffle types and numerical results obtained for single baffle were compared with Kern analytical method results. Heat convection coefficient and pressure drop were investigated in using single, disc and dougnut baffle. The effect of mesh on heat transfer was examined and it was seen that fine mesh gave better results. Comparisons of turbulence models were made and the $k-\varepsilon$ turbulence model which gives better results used in all analyzes.
\end{abstract}

Keywords: Shell and tube heat exchanger, computational fluid dynamics (CFD), single, disc and dougnut baffle

\section{Giriş}

Is1 değiştiricileri farklı sıcaklıklarda, birbirinden katı cidar ile ayrılmış iki akışkan arasındaki ısı transferini sağlayan cihazlardır. Isı değiştiricileri 1sıtma, soğutma, havalandırma, ısı depolama sistemleri gibi alanlarda kullanılmaktadır. Gövde - boru tipi 1sı değiştiricileri; gövde eksenine paralel olarak

\footnotetext{
*Sorumlu yazar: tugcek001@gmail.com

Geliş Tarihi: 01.02.2021, Kabul Tarihi: 17.08.2021
} 
yerleştirilmiş çok sayıda borulardan oluşmaktadır. Bir akışkan boru içerisinden, diğeri boruların dışında gövde boyunca akarken 1sı transferi meydana gelir. Gövde - boru tipi 1s1 değiştiricileri oldukça büyük 1s1 transfer alanına sahip olmaları, kolay temizlenebilir olma özellikleri ile tercih edilmektedir. Is1 transferini iyileştirmek, borulara destek olmak, borular arasındaki uniform aralı̆̆ korumak, gövde tarafındaki akışkanı borulara göre paralel ve çapraz akmaya zorlayacak şekilde gövde içerisine şaşırtma levhaları yerleştirilir [1]. Şaşırtma levhası, akışkanın hareketini etkileyip türbülans oluşturmaktadır. Türbülansın artması 1sı transferini arttırmaktadır. Gövde çapı, boru çapı, uzunluğu, şaşırtma levhası tipi, sayısı, kesme oranının birbiriyle olan kombinasyonlarıyla verimli bir isı transferi gerçekleşecektir. Değişken parametrelerin sayısal analizleri HAD yöntemiyle yapılarak sonuçlar alınabilir. Hesaplamalı akışkanlar dinamiği yöntemiyle deney maliyetlerinden, zamandan tasarruf sağlanmasına rağmen, sayısal sonuçların deneysel ve analitik sonuçlarla doğrulanması gerekir. Yapılan çalışmalarda türbülans modelleri için sayısal analizler yapılmış, yapılan analizler sonucunda en uygun türbülans modeli olarak $k-\varepsilon$ modeli seçilmiştir [2]. Standart $k-\varepsilon$ türbülans modelinde; $k$ : türbülans kinetik enerjisini $\varepsilon$ : kinetik enerjinin yayılım hızını ifade eder. Türbülans modellerinin 1s1 transferindeki öneminin araştırılması yapılmış, farklı türbülans modelleri kullanılarak yapılan analizlerde $k-\varepsilon$ modelinin en uygun model olduğu belirlenmiştir [3]. Şaşırtma levha tiplerinin 1s1 transferine etkisi araştırılmış, iki farklı şaşırtma levhası kullanılarak (perde desenli, düz) aynı şartlar altındaki sonuçlara bakılmış, perde desenli levhanın daha verimli olduğu belirlenmiştir [4]. Tek parçalı, iki parçalı, üç parçalı, helisel, flower tipi şaşırtma levhalı 1sı değiştiricilerinin HAD analizi yapılıp 1sı transfer katsayıları ve basınç düşümleri incelenmiştir. Yapılan analizler sonucunda tek parçalı şaşırtma levhasının en verimli olduğu ortaya çıkmıştır [5]. Şaşırtma levhalarının yatay ve dikey yerleştirilmesi incelenmiş. Yatay yerleştirilmesinin basınç düşümü ve Nusselt sayısının arttığı gözlemlenmiştir [6]. Şaşırtma levhalarının yerleştirilme açıları incelenmiş yapılan analizler sonucunda $20^{\circ}$ 'lik açının optimum olduğu belirlenmiştir [7]. Helisel şaşırtma levhasının 1sı transferine etkisi araştırılmış ve helisel tipin türbülansı arttırdığı, 1sı transferini iyileştirdiği belirlenmiştir [8]. Tek parçalı, iki parçalı, disk ve halka şeklindeki şaşırtma levhalarının HAD analizleri yapılmış ve yeni geometriler üzerinde çalışmalar yapılmıştır [9]. Tek parçalı, iki parçalı, helisel şaşırtma levhaları arasında karşılaştırmalar yapılmış helisel şaşırtma levhasının daha iyi sonuçlar verdiği görülmüştür [10]. Parçalı, flower, ring, trefoil hole, halka, helisel tipi şaşırtma levhaları kullanılan gövde borulu 1sı değiştiricisinde en verimli levhanın helisel olduğu belirlenmiştir [11]. Şaşırtma levhalarının parçalı, helisel olarak yerleştirilmesi, şaşırtma levhaları arası mesafe HAD ve analitik yöntemlerle karşılaştırılması yapılmış helisel yerleştirilmenin parçalı şaşırtma levhasına alternatif olabileceği belirlenmiştir [12]. Boru düzenleri, kesme oranları, levha tiplerinin 1s1 transferine etkisi incelenmiştir, tek parçalı ve iki parçalı gibi şaşırtma levhalarından optimum olan belirlenmiştir [13]. Gövde borulu isı değiştiricilerinde farklı tiplerde (tek parçalı, iki parçalı, dikey) şaşırtma levhaları ve farklı şaşırtma levhası kesmeleri kullanarak HAD programı ile sonuçları karşılaştırmışıtır [14]. Eliptik ve parçalı şaşırtma levhalı 1sı değiştiricisinin HAD ve deneysel sonuçları karşılaştırılmış eliptik levhanın daha iyi isı transferi sağladığı görülmüştür.

Bu çalışmada katı modeli oluşturulan gövde - boru tipi isı değiş̧tiricilerinde tek parçalı, disk ve halka şeklindeki şaşırtma levhası kullanılmasının HAD analiz sonuçları üzerindeki etkileri incelenmiştir. Farklı hız, türbülans ve ağ yapısı kullanılan modelin hesaplamalı akışkanlar dinamiği paket programında sayısal analizleri yapılmıştır. Oluşturulan modelde; ağ yapıları ve sınır şartları belirlenip analiz başlatılmıştır. Model karmaşı yüzeylerden oluştuğu için ağ yapısı; tetragonal seçilmiştir. Boru yüzeyleri, gövde ayrı olarak seçilen ağ boyutlarıyla oluşturulmuştur. Ağ boyutu, ağ kalitesi değiştirilerek sonuçlar incelenmiştir. Farklı şaşırtma levha tiplerine göre oluşturulan ağların eleman sayıları farklı çıkmıştır. Eleman sayısı; tek parçalı şaşırtma levhası için ağ boyutlarına göre 145 000 ile 2258 426, disk ve halka şeklindeki şaşırtma levhası için 90418 ile 2290870 arasında değişmektedir. Skewness oranı 0.79 ile 0.81 arasında değişmektedir. Sınır şartları: akışkanın gövde içerisine giriş sıcaklığı $300 \mathrm{~K}$, giriş hızı dağılımı uniform, kaydırmazlık şartı, sabit duvar sıcaklığ 450 $K$, türbülans modeli standart $k-\varepsilon$, malzeme olarak çelik, akışkan olarak su seçilmiş ve hız değeri değişken olarak belirlenmiştir. Çıkış basıncı 0 olarak alınıp basınç düşümü analizler sonucunda belirlenmiştir. Yapılan analizler sonucunda değişken parametrelerin 1S1 transferine, 1S1 taşınım katsayısına, basınç düşümlerine olan etikleri incelenmiştir. Sayısal analizler ANSYS 14.5 paket programı kullanılarak yapılmıştır. Tek parçalı şaşırtma levhalı 1sı değiştiricisi için sayısal sonuçlar analitik (Kern) sonuçlarla karşıllaştırılmıştır. 


\section{Materyal ve Metot}

Çalışmada küçük bir gövde - boru tipi 1sı değiştiricisinde; tek parçalı, disk ve halka şeklindeki şaşırtma levhaları kullanımının ısı transferine, basınç düşümüne olan etkisi incelenmiştir. Akış analizleri ANSYS Fluent programında yapılmıştır. Sayısal analizin yapılması için gerekli olan katı model (1sı değiştirici) SOLIDWORKS programında çizilmiş ve model ANSYS programına getirilmiştir. Hesaplamalı Akışkanlar Dinamiği (HAD) numerik analiz ve algoritmalar kullanılarak akışkan davranışları ile ilgili problemleri, bilgisayar simülasyonları vasıtası ile analiz edip çözme amaçlı bir mühendislik çalışmasıdır. Hesap kolaylığı sağlayan HAD programı, gövde - boru tipi 1sı değiştiricilerinin de 1sıl analizinin yapılmasını sağlamaktadır.

Çalışmada yedi tane borunun üçgensel düzende yerleştirildiği gövde - boru tipi 1sı değiştiricisi oluşturulmuştur. İki farklı tipteki şaşırtma levhası kullanılarak oluşturulan gövde - boru tipi 1S1 değiştiricisinin HAD analizi yapılmıştır. Şekil 1, Şekil 2'de ve Şekil 3'te boru düzeni, tek parçalı ve disk halka biçimindeki şaşırtma levhası kullanılan gövde - boru tipi 1sı değiştiricilerin modellemesi verilmiştir. Şekil 1'deki boru düzeninde 7 tane boru kullanılmıştır, Boru düzeni = Eşkenar üçgen, Şekil 4, Şekil 5 'te tek parçalı ( kesme oranı $\mathrm{B}_{\mathrm{c}}=\% 30$ ), disk ve halka şaşırtma levhasının şematik resimleri verilmiştir. HAD analizleri yapılırken farklı hız, türbülans modeli, ağ yapısı, iterasyon sayısının analizi nasıl etkilendiği incelenmiştir. HAD programında iterasyon sayıları 100, 2000, 5000, 10000, 15000 alınarak analizler yapılmıştır. HAD programında farklı türbülans modelleri kullanılarak analizler yapılıp türbülans modellerinin analize olan etkileri inceleniştir. $k-\varepsilon$ standart türbülans modeli analiz sonuçlarının analitik sonuçlarla daha iyi eşleştiği görülmüştür. Farklı durumlar için yapılan analizlerde $k-\varepsilon$ standart türbülans modeli kullanılmıştır. Şekil 6 ve Şekil 7'de farklı tiplerdeki şaşırtma levhası kullanılan 1sı değiştiricisinin Fluent programında oluşturulan ağ yapısı verilmiştir. Model olarak belirlenen gövde - boru tipi 1sı değiştiricisinin ağ yapısı belirlenip, giriş parametreleri girilip, analize başlanmıştır. Tek parçalı şaşırtma levhasının HAD uygulamasından alınan sonuçları Kern analitik yöntemiyle karşılaştırılmıştır.
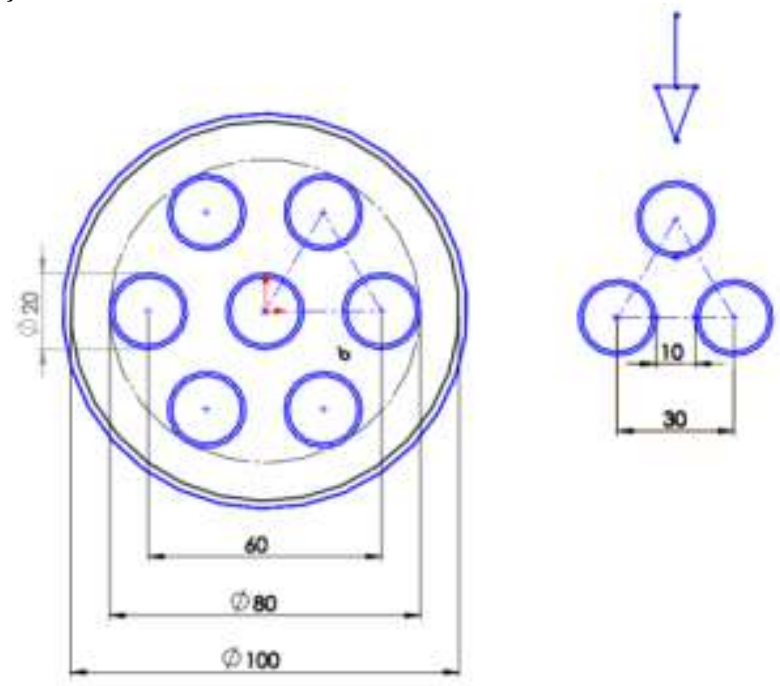

Şekil 1. Gövde - boru tipi 1sı değiştiricisinin boru düzeni verileri
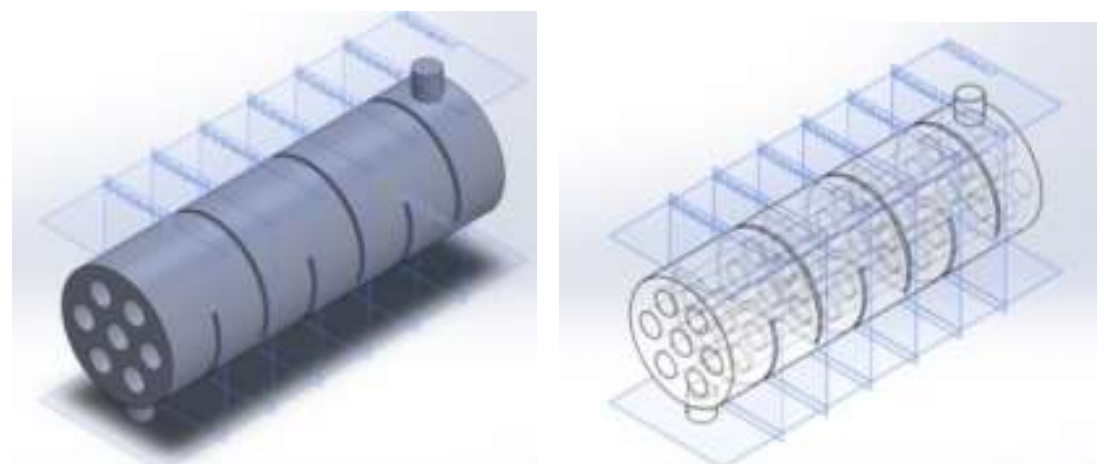

Şekil 2. Tek parçalı (altı adet) şaş̧rtma levhalı gövde - boru tipi 1sı değiştiricisi 

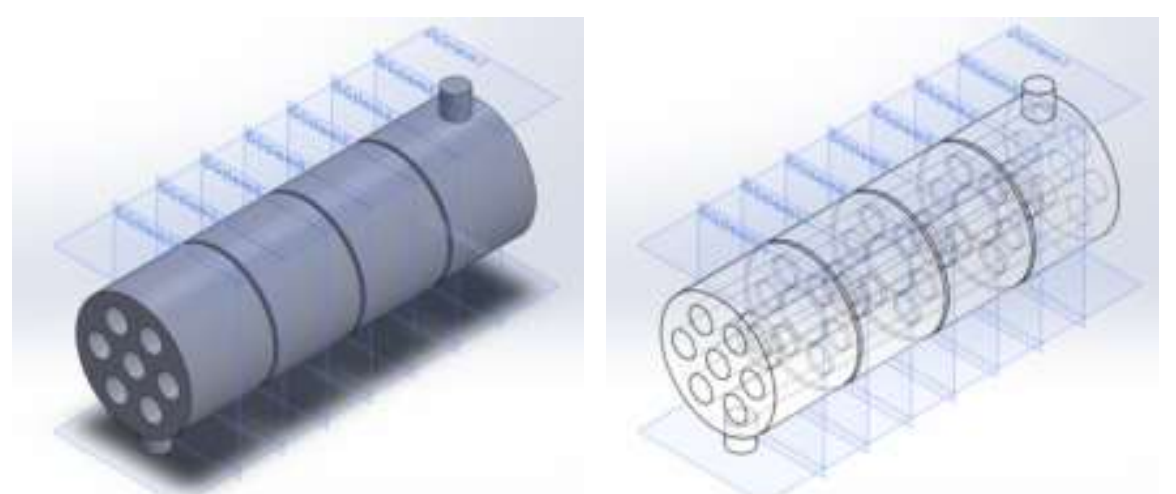

Şekil 3. Disk ve halka şaşırtma levhalı gövde - boru tipi 1sı değiştiricisi
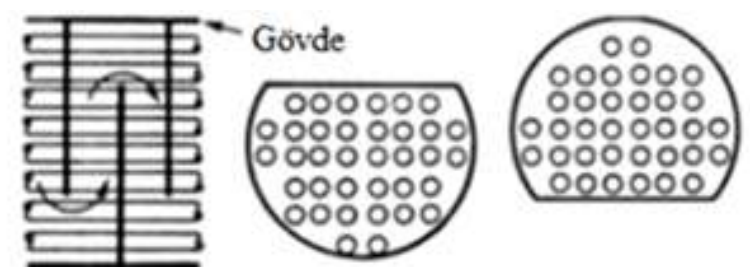

Şekil 4. Tek parçalı şaşırtma levhası
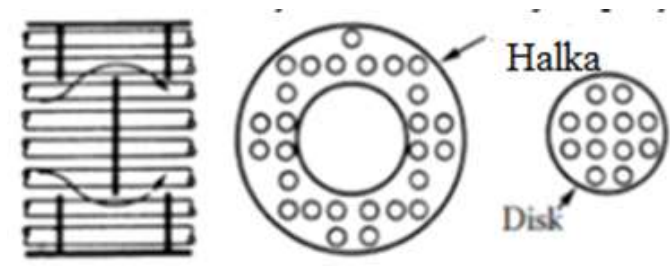

Şekil 5. Disk ve halka şaşırtma levhası

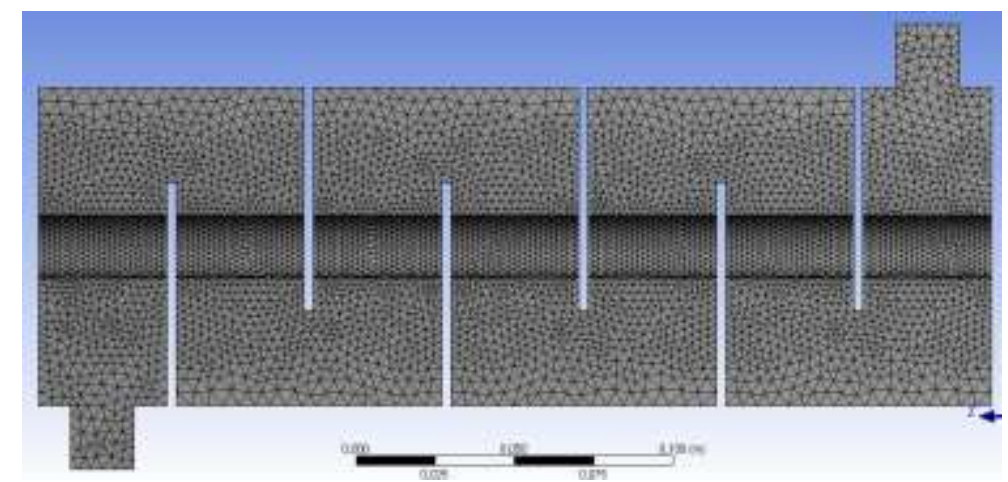

Şekil 6. Tek parçalı (6 adet) şaşırtma levhalı gövde - boru tipi ısı değiştiricisinin ağ yapısı

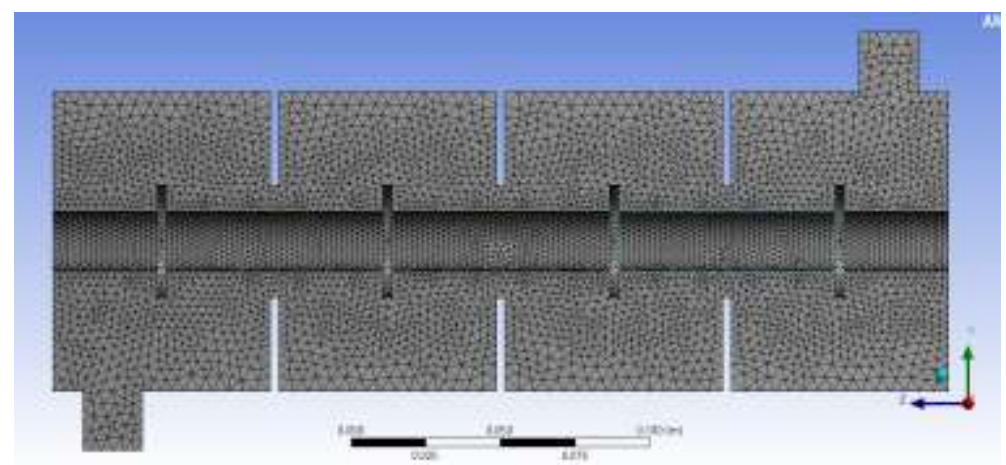

Şekil 7. Disk ve halka şaşırtma levhalı gövde - boru tipi 1sı değiştiricisinin ağ yapısı 
Tek parçalı, $\mathrm{B}_{\mathrm{c}}=\% 30$ kesme oranlı, $\mathrm{N}_{\mathrm{b}}=6$ adet şaşırtma levhasının kullanıldığı gövde - boru tipi 1s1 değiştiricilerinin Kern yöntemine göre 1sı taşınım katsayısının hesabı aşağıda verilmiştir. Gövde tarafı ısı taşınım katsayısı için aşağıdaki korelasyon denklemi kullanılmıştır [16].

$N u=\frac{h_{0} D_{e}}{k}=0.36\left(\frac{D_{e} G_{s}}{\mu}\right)^{0.55}\left(\frac{c_{p} \mu}{k}\right)^{1 / 3}\left(\frac{\mu}{\mu_{w}}\right)^{0.14}$

$2 \times 10^{3}<R e_{s}=\frac{G_{s} D_{e}}{\mu}<1 \times 10^{6}$

Burada, $D_{e}$ gövde tarafı eşdeğer çap, $G_{s}$ is gövde tarafı kütle hızı ve $R e_{s}$ gövde tarafi Reynolds sayısıdır. $30^{\circ}$ üçgen adımlı boru düzeni için eşdeğer çap ve kütle akış hızı Eşitlik (2) ve (3) de verilmiştir.

$D_{e}=\frac{4 \times \text { Serbest akışalanı }}{\text { Islak çevre }}=\frac{4\left(\frac{\sqrt{3} P_{t}^{2}}{4}\right)-\frac{\pi d_{0}{ }^{2}}{8}}{\pi d_{0} / 2}$

$G_{S}=\frac{\dot{m}}{A_{s}}$

Burada, $d_{o}$ : boru dış çapı, $P_{T}$ : boru adımı, $\dot{m}$ : kütlesel debi, $A_{s}$ : gövde merkezindeki akış kesit alanıdır. Gövde merkezindeki akış kesit alanı Eşitlik (4)' de verilmiştir.

$A_{s}=\left(D_{s}-N_{t c} d_{0}\right) B$

Eşitlik (4) de, $D_{s}$ : gövde iç çapı, $N_{t c}$ : gövde merkezindeki boru sayısı ve $B$ şaşırtma levha aralığı olarak tanımlanmaktadır.

Sayısal olarak HAD programından alınan sonuçlara göre, 1sı değiştiricisinin 1sı taşınım katsayısı ise toplam 1sı geçiş katsayısı denklemi kullanılarak hesaplanabilir. Toplam ısı geçiş katsayısı denklemi 1s1 değiştiricilerinde,

$$
\frac{1}{U}=\frac{1}{h_{o}}+\frac{d_{o} \cdot \ln \left(d_{o} / d_{i}\right)}{2 k}+\frac{d_{o}}{d_{i}} \frac{1}{h_{i}}
$$

bağıntısı ile hesaplanabilir. Burada, $h_{o}$ ve $h_{i}$ sırasılyla gövde ve boru tarafı 1sı taşınım katsayısıdır. Boru yüzey sıcaklığı sabit olduğundan, ısı iletim direnci ve boru tarafı taşınım direnci $\left(h_{i}\right)$ sadeleştirilirse, toplam ısı geçiş katsayısı aşağıdaki gibi ifade edilebilir.

$\frac{1}{U}=\frac{1}{h_{o}} \quad U=h_{o}$

Eğer enerji ve 1sı transfer denklemleri kullanılarak ısı taşınım katsayısı,

$Q=\dot{m} c_{p} \Delta T_{s}=U A \Delta T_{l n}=h_{o} A \Delta T_{l n}$

$h_{o}=\frac{Q}{A \Delta T_{l n}}=\frac{\dot{m} c_{p} \Delta T_{c}}{A \Delta T_{l n}}$

denklemi ile hesaplanabilir. Burada, $\Delta T_{c}=T_{c 2}-T_{c 1}$ : gövde tarafı akışkanın çıkış ve girişindeki sıcaklık farkıdır, $\Delta T_{l n}$ logaritmik ortalama sicaklık farkı ve A toplam 1sı transfer yüzey alanıdır. Yapılan sayısal hesaplamalarda HAD programından akışkanın çıkış sıcaklığı alınarak, logaritmik ortalama 
sıcaklık farkı Eşitlik (9) dan hesaplanmıştır. Eşitlik (8) deki toplam ısı transfer yüzey alanı ise Eşitlik (10) da verilmiştir.

$\Delta T_{l n}=\frac{\left(T_{w}-T_{c 1}\right)-\left(T_{w}-T_{c 2}\right)}{\ln \frac{\left(T_{w}-T_{c 1}\right)}{\left(T_{w}-T_{c 2}\right)}}$

$A_{o}=N \pi d_{o} L$

Burada, $T_{w}$ : boru yüzey sıcaklığı, N: boru sayısı ve $d_{o}$ : boru dış çapıdır.

Yapılan analitik hesaplamada, gövde tarafı akışkan su olarak alınmış, suyun çıkış sıcaklığı, boru yüzey sıcaklığı ve suyun giriş sıcaklığının aritmetik ortalaması alınarak ilk önce kabul edilmiştir. Daha sonra ortalama akışkan sıcaklığı hesaplanarak suyun termofiziksel özellikleri Excel programında özellikler için yazılan makro programlar kullanılarak interpolasyonla akışkan tablosundan hesaplanmıştır. Akışkan özellikleri ile Eşitlik (1)' den Nusselt sayısı $(\mathrm{Nu})$ ve isı taşınım katsayısı $\left(h_{o}\right)$ hesaplanmıştır. Daha sonra, hesaplanan $h_{o}$ değeri Eşitlik (7)' de yerine yazılarak tekrar Newton Raphson yöntemi ile gövde tarafi akışkanın çıkış sıcaklığı hesaplanmış ve kabul edilen değerle karşılaştırılmıştır. İteratif bir işlemle hesaplar tekrarlanarak, analitik olarak suyun çıkış sıcaklığı bulunmuştur.

\section{Bulgular ve Tartışma}

Çalışmalarda; tek parçalı, disk ve halka şaşırtma levhası kullanılarak oluşturulan gövde - boru tipi isı değiştiricilerinin analiz sonuçlarının 1sı taşınım katsayısı ve basınç düşümüne olan etkileri incelenmiştir. Farklı hız, türbülans, ağ yapısı, iterasyon sayılarının ısı transferine olan etkileri incelenmiştir.

Tek parçalı, $\mathrm{B}_{\mathrm{c}}=\% 30$ kesme oranlı, $\mathrm{N}_{\mathrm{b}}=6$ adet şaşırtma levhasının kullanıldı $\breve{g} 1$ gövde - boru tipi 1sı değiştiricilerinin Kern yöntemine göre 1sı taşınım katsayısının hesabı aşağıda verilmiştir. Gövde tarafi 1sı taşınım katsayısı için aşağıdaki korelasyon denklemi kullanılmıştır [16].

Yapılan analitik ve sayısal hesaplamalarda, gövde - boru tipi 1sı değiştirici modeli için aşağıda verilen özellikler sabit alınmıştır:

Boru düzeni $=$ Eşkenar üçgen, gövde çapı: $D_{s}=0.100 \mathrm{~m}$, boru çapı: $d_{0}=0.020 \mathrm{~m}$, boru sayısı: $N_{T}=$ 7, boru geçiş sayısı: $N_{P}=1$, boru uzunluğu: $L=0.3 \mathrm{~m}$, gövde tarafı giriş sıcaklığı: $T_{c 1}=300 \mathrm{~K}$, boru yüzey sıcaklığı: $T_{w}=450 \mathrm{~K}$

\subsection{Tek Parçalı Şaşırtma Levhalı Gövde - Boru Tipi Isı Değiştiricileri}

Yapılan hesaplamalarda $\mathrm{B}_{\mathrm{c}}=\% 30$ kesme oranlı, $\mathrm{N}_{\mathrm{b}}=6$ adet şaşırtma levhası kullanılarak oluşturulan tek parçalı şaşırtma levhalı gövde - boru tipi ısı değiştirici için analiz sonuçları sırasıyla Tablo 2, Tablo 3 ve Tablo 4'te verilmiştir. Tek parçalı şaşırtma levhalı gövde - boru tipi isı değiştiricisi kullanılarak yapılan analizlerde türbülans modelleri, ağ yapısı, iterasyon sayısının 1sı taşınım katsayısı ve basınç düşümüne etkisi incelenmiş, optimum değerler belirlenerek diğer analizlerde o değerler kullanılmıştır.

Tablo 1'de hız değerinin artması ile basınç düşümü, 1sı taşınım katsayısı ve 1sı transfer miktarı artmıştır, çıkış sıcaklığı azalmıştır. Sayısal ve analitik sonuçların birbirleriyle uyum gösterdiği görülmüştür. Sırasıyla Şekil 8, Şekil 9, Şekil 10'da sayısal ve analitik sonuçlara göre çıkış sıcaklıkları, 1sı taşınım katsayısı, basınç düşüm değişimleri verilmiştir.

Tablo 1. Farklı giriş hızına göre HAD ve Kern sonuçları $\left(\mathrm{N}_{\mathrm{b}}=6, \mathrm{~B}_{\mathrm{c}}=\% 30\right)$

\begin{tabular}{cccccc}
\hline $\begin{array}{l}\mathbf{H} \text { (zz } \\
(\mathbf{m} / \mathbf{s})\end{array}$ & $\begin{array}{c}\mathbf{T}_{\mathbf{c} 2 \text {,analitik }} \\
(\mathbf{K})\end{array}$ & $\begin{array}{c}\mathbf{T}_{\mathbf{c} 2, \text { HAD }} \\
(\mathbf{K})\end{array}$ & $\begin{array}{c}\mathbf{h}_{\text {analitik }} \\
\left(\mathbf{W} / \mathbf{m}^{2} \mathbf{K}\right)\end{array}$ & $\begin{array}{c}\mathbf{h}_{\text {HAD }} \\
\left(\mathbf{W} / \mathbf{m}^{\mathbf{2}} \mathbf{K}\right)\end{array}$ & $\begin{array}{c}\Delta \mathbf{P}_{\text {HAD }} \\
(\mathbf{P a})\end{array}$ \\
\hline 0.3 & 350.1 & 355 & 1199 & 1204 & 147 \\
0.5 & 340.97 & 341 & 1570.02 & 1571.01 & 398 \\
1.0 & 330.84 & 330 & 2270 & 2267 & 1578 \\
1.5 & 326.01 & 333 & 2820 & 2841 & 3482 \\
\hline
\end{tabular}




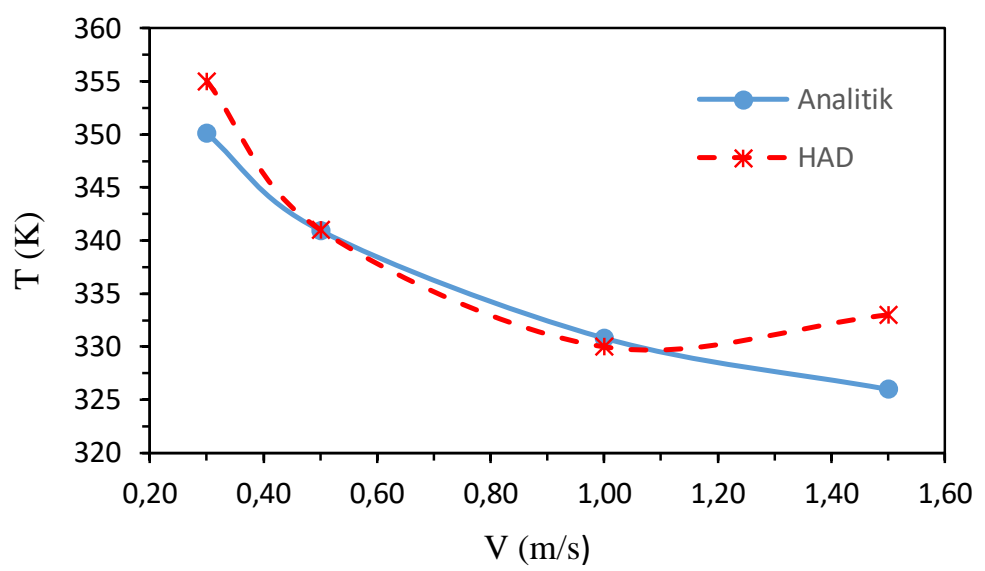

Şekil 8. Tek parçalı şaşırtma levhalı gövde - boru tipi ısı değiştiricisinin giriş hızına göre çıkış sıcaklıkları

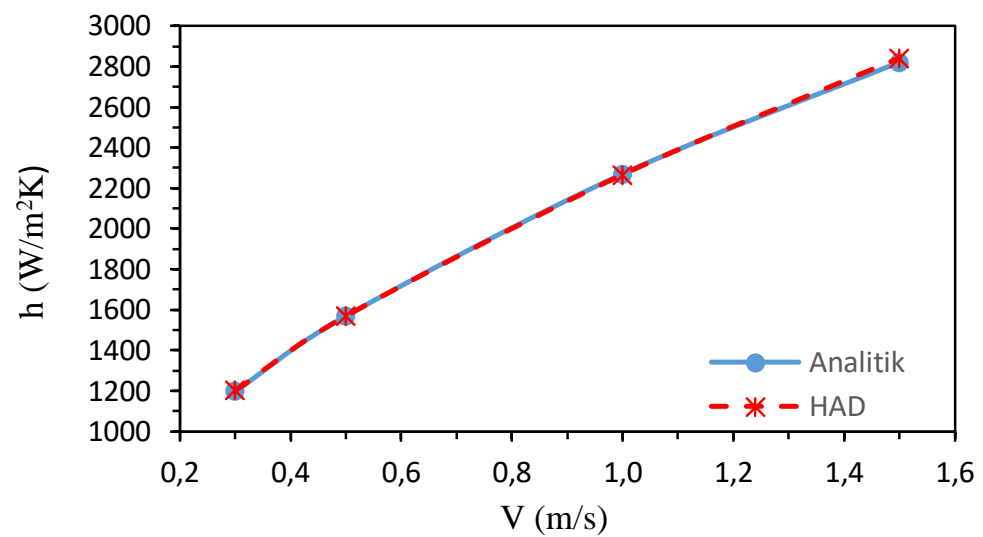

Şekil 9. Tek parçalı şaşırtma levhalı gövde - boru tipi ısı değiştiricisinin giriş hızına göre ısı taşınım katsayıları

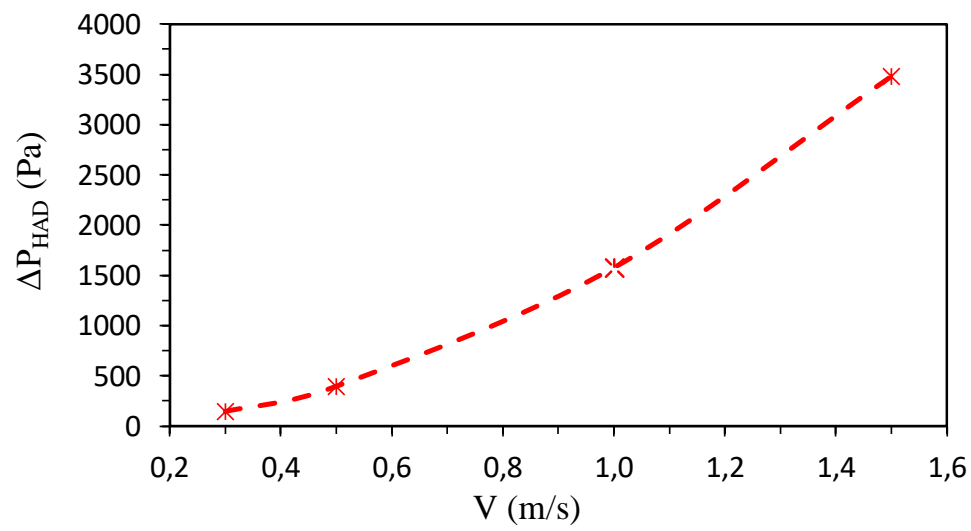

Şekil 10. Tek parçalı şaşırtma levhalı gövde - boru tipi ısı değiştiricisinin giriş hızına göre basınç düşümleri

Tablo 2'de ağ yapısının sıkılaşması ile eleman sayısı artmış, eleman sayısının artması ile analiz süresi artmıştır. Analitik sonuçlarla HAD sonuçlarının uyumlulukları değerlendirildiğinde ağ boyutu boru yüzeyinde $0.002 \mathrm{~m}$ gövde içerisinde de $0.005 \mathrm{~m}$ alınabilir. Yapılan diğer analizlerde $0.002-0.005 \mathrm{~m}$ olarak belirlenen ă̆ boyutu kullanılmıştır.

Tablo 2. Farklı ağ yapılarına göre HAD ve Kern sonuçları $\left(\mathrm{N}_{\mathrm{b}}=6, \mathrm{~B}_{\mathrm{c}}=\% 30, \mathrm{~V}=1 \mathrm{~m} / \mathrm{s}\right)$

\begin{tabular}{cccccc}
\hline $\begin{array}{c}\text { Ăg Yapısı } \\
(\mathbf{m})\end{array}$ & $\begin{array}{c}\mathbf{T}_{\text {c2,analitik }} \\
(\mathbf{K})\end{array}$ & $\begin{array}{c}\mathbf{T}_{\text {c2,HAD }} \\
(\mathbf{K})\end{array}$ & $\begin{array}{c}\mathbf{h}_{\text {analitik }} \\
\left(\mathbf{W} / \mathbf{m}^{\mathbf{2}} \mathbf{K}\right)\end{array}$ & $\begin{array}{c}\mathbf{h}_{\text {HAD }} \\
\left(\mathbf{W} / \mathbf{m}^{\mathbf{2}} \mathbf{K}\right)\end{array}$ & $\begin{array}{c}\Delta \mathbf{P}_{\text {HAD }} \\
(\mathbf{P a})\end{array}$ \\
\hline $0.002-0.005$ & 330.84 & 330 & 2270 & 2267 & 1578 \\
$0.004-0.008$ & 330.84 & 332 & 2270 & 2273 & 1552 \\
$\begin{array}{l}\text { Kaba ăg-düşük } \\
\text { pürüzlülük }\end{array}$ & 330.84 & 333 & 2270 & 2276 & 1529 \\
\hline
\end{tabular}


Tablo 3 'te HAD programında farklı türbülans modelleri kullanılarak, türbülans modellerinin analiz sonuçlarına etkisi incelenmiştir. $k-\varepsilon$ standart türbülans modelinde analitik ve sayısal sonuçların birbirleriyle daha uyumlu olduğu görülmüştür. Farklı durumlar için yapılan analizlerde $k-\varepsilon$ standart türbülans modeli kullanılarak hesaplamalar yapılmıştır.

Tablo 3. Farklı türbülans modellerine göre HAD ve Kern sonuçları $\left(\mathrm{N}_{\mathrm{b}}=6, \mathrm{~B}_{\mathrm{c}}=\% 30, \mathrm{~V}=1 \mathrm{~m} / \mathrm{s}\right)$

\begin{tabular}{lccccc}
\hline $\begin{array}{l}\text { Türbülans } \\
\text { modeli }\end{array}$ & $\begin{array}{c}\mathbf{T}_{\mathbf{c 2} \text {,analitik }} \\
(\mathbf{K})\end{array}$ & $\begin{array}{c}\mathbf{T}_{\mathbf{c 2}, \text { HAD }} \\
(\mathbf{K})\end{array}$ & $\begin{array}{c}\mathbf{h}_{\text {analitik }} \\
\left(\mathbf{W} / \mathbf{m}^{\mathbf{2}} \mathbf{K}\right)\end{array}$ & $\begin{array}{c}\mathbf{h}_{\text {HAD }} \\
\left(\mathbf{W} / \mathbf{m}^{\mathbf{2}} \mathbf{K}\right)\end{array}$ & $\begin{array}{c}\Delta \mathbf{P}_{\text {HAD }} \\
(\mathbf{P a})\end{array}$ \\
\hline$k-\varepsilon$ standart & 330.84 & 330 & 2270 & 2267 & 1578 \\
$k-\varepsilon$ realizable & 330.84 & 334 & 2270 & 2279 & 1542 \\
$k-w$ standart & 330.84 & 334 & 2270 & 2279 & 1463 \\
Spalarat Allmaras & 330.84 & 329 & 2270 & 2265 & 1421 \\
\hline
\end{tabular}

Tablo 4'te iterasyon sayısının artması ile analiz süreleri artmıştır. İterasyon sayısı belirli seviyeye geldikten sonra sonuçların çok fazla değişmediği ve analizin doğrulandıği görülmüştür. Yapılacak diğer analizlerde 10000 iterasyon sayısı kullanılarak hesaplamalar yapılmıştır.

Tablo 4. Farklı iterasyon sayılarına göre $H A D$ ve Kern sonuçları $\left(\mathrm{N}_{\mathrm{b}}=6, \mathrm{~B}_{\mathrm{c}}=\% 30, \mathrm{~V}=1 \mathrm{~m} / \mathrm{s}\right)$

\begin{tabular}{cccccc}
\hline $\begin{array}{c}\text { Itterasyon } \\
\text { Sayıs }\end{array}$ & $\begin{array}{c}\mathbf{T}_{\mathbf{c} 2 \text {, analitik }} \\
(\mathbf{K})\end{array}$ & $\begin{array}{c}\mathbf{T}_{\mathbf{c} 2 \text {,HAD }} \\
(\mathbf{K})\end{array}$ & $\begin{array}{c}\mathbf{h}_{\text {analitik }} \\
\left(\mathbf{W} / \mathbf{m}^{2} \mathbf{K}\right)\end{array}$ & $\begin{array}{c}\mathbf{h}_{\text {HAD }} \\
\left(\mathbf{W} / \mathbf{m}^{\mathbf{2}} \mathbf{K}\right)\end{array}$ & $\begin{array}{c}\Delta \mathbf{P}_{\text {HAD }} \\
(\mathbf{P a})\end{array}$ \\
\hline 100 & 330.84 & 356 & 2270 & 2337 & 2030 \\
2000 & 330.84 & 334 & 2270 & 2279 & 1560 \\
5000 & 330.84 & 330 & 2270 & 2267 & 1578 \\
10000 & 330.84 & 334 & 2270 & 2279 & 1565 \\
15000 & 330.84 & 334 & 2270 & 2279 & 1565 \\
\hline
\end{tabular}

Şekil 11'de HAD programından alınan raporlara göre; tek parçalı şaşırtma levhalı gövde - boru tipi 1sı değiştiricisinin hız akım çizgileri ve sıcaklık dağılımları verilmiştir.
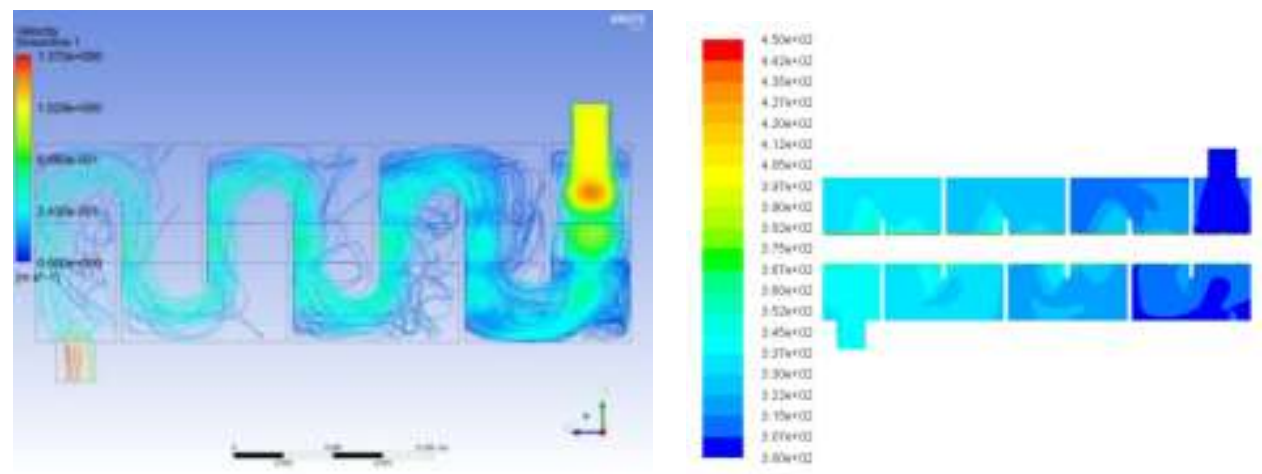

Şekil 11. Tek parçalı şaşırtma levhalı gövde - boru tipi ısı değiştiricisinin hız akım çizgileri ve sıcaklık dağılımı

\subsection{Disk ve Halka Şaşırtma Levhalı Gövde - Boru Tipi Isı Değiştiricileri}

Disk ve halkalı şaşırtma levhası kullanılarak oluşturulan gövde - boru tipi 1sı değiştiricisinde HAD analizleri yapılmış analiz sonuçları sırasıyla Tablo 5 ve Tablo 6'da verilmiştir.

Tablo 5'te giriş hızı arttıkça çıkış sıcaklığının azaldığı, 1Sı taşınım katsayısının ve basınç düşümünün arttığı görülmüştür. Sırasıyla Şekil 12, Şekil 13, Şekil 14'de analitik sonuçlara göre çıkış sıcaklıkları, 1Sı taşınım katsayısı, basınç düşüm değişimleri verilmiştir. Hızın artmasıyla, çıkış sıcaklığı azalmıştır, 1sı taşınım katsayısı artmıştır, basınç düşümü artmıştır. 
Tablo 5. Farklı giriş hızına göre HAD

\begin{tabular}{cccc}
\hline $\mathbf{H z z}$ & $\mathbf{T}_{\mathbf{2} 2 \text {,HAD }}$ & $\begin{array}{c}\mathbf{h}_{\text {HAD }} \\
\left(\mathbf{W} / \mathbf{m}^{\mathbf{2}} \mathbf{K}\right)\end{array}$ & $\begin{array}{c}\Delta \mathbf{P}_{\text {HAD }} \\
(\mathbf{P a})\end{array}$ \\
\hline 0.3 & $\mathbf{( K )}$ & 1042 & 147 \\
0.5 & 355 & 1324 & 400 \\
1.0 & 342 & 2111 & 1538 \\
1.5 & 334 & 3038 & 3405 \\
\hline
\end{tabular}

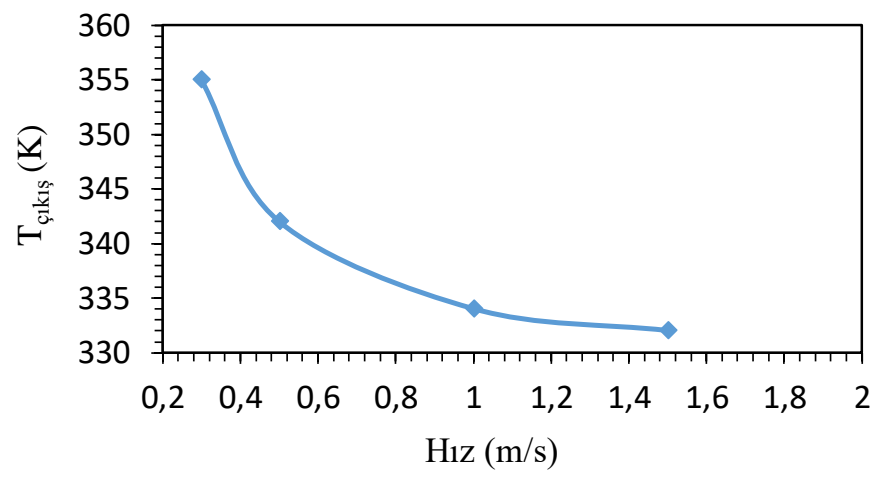

Şekil 12. Disk ve halka şaşırtma levhalı gövde - boru tipi 1sı değiştiricisinin giriş hızına göre çıkış sıcaklıkları

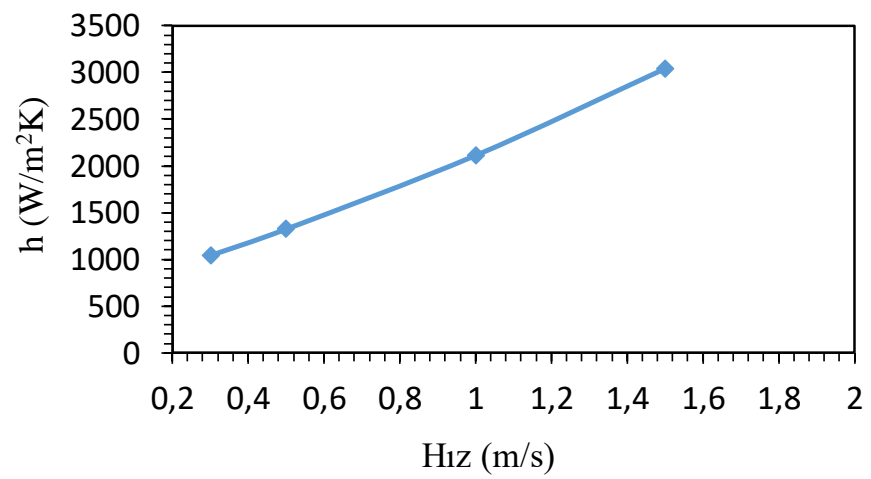

Şekil 13. Disk ve halka şaşırtma levhalı gövde - boru tipi ısı değiştiricisinin giriş hızına göre 1sı taşınım katsayıları

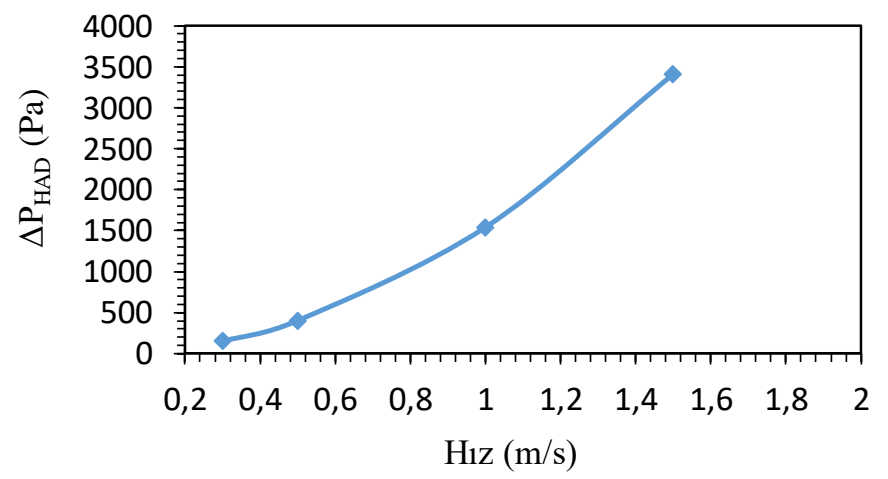

Şekil 14. Disk ve halka şaşırtma levhalı gövde - boru tipi 1sı değiştiricisinin giriş hızına göre basınç düşümleri

Tablo 6'da farklı ağ boyutlarının analize etkileri incelenmiştir. Birinci durumda (0.001 - 0.002 m) çok sıkı mesh (ăg) yapıldığı zaman analiz süresinin arttı̆̆ gözlemlenmiştir. İkinci (0.002 - $0.004 \mathrm{~m})$ ve üçüncü (0.002 - $0.005 \mathrm{~m})$ durumlarda analiz sonuçlarının çok fazla değişmediği görülmüştür. Yapılan diğer analizlerde üçüncü durumdaki ağ yapısı kullanılmıştır. Ağ yapısı seçimlerinde boru yüzeyi 0.002 m, gövde içerisi 0.005 m alınabilir. Sırasıyla Şekil 15, Şekil 16, Şekil 17'de analitik sonuçların grafiksel 
olarak değişimleri verilmiştir. Şekil 15, Şekil 16, Şekil 17'de ağ yapısı sıkılığı azaldıkça çıkış sıcaklığ azalmıştır, 1sı taşınım katsayısı azalmışıı, basınç düşümü azalmıştır.

Tablo 6. Farklı ăg yapılarına göre HAD sonuçları $(\mathrm{V}=1 \mathrm{~m} / \mathrm{s})$

\begin{tabular}{ccccc}
\hline $\begin{array}{c}\text { Durum } \\
\text { No }\end{array}$ & $\begin{array}{c}\text { Ăg Yapisi } \\
(\mathbf{m})\end{array}$ & $\begin{array}{c}\mathbf{T}_{\mathbf{c} 2, \text { HAD }} \\
(\mathbf{K})\end{array}$ & $\begin{array}{c}\mathbf{h}_{\text {HAD }} \\
\left(\mathbf{W} / \mathbf{m}^{2} \mathbf{K}\right)\end{array}$ & $\begin{array}{c}\Delta \mathbf{P H A D} \\
(\mathbf{P a})\end{array}$ \\
\hline 1. & $0.001-0.002$ & 340 & 2570 & 1579 \\
2. & $0.002-0.004$ & 333 & 2151 & 1540 \\
3. & $0.002-0.005$ & 334 & 2111 & 1538 \\
\hline
\end{tabular}

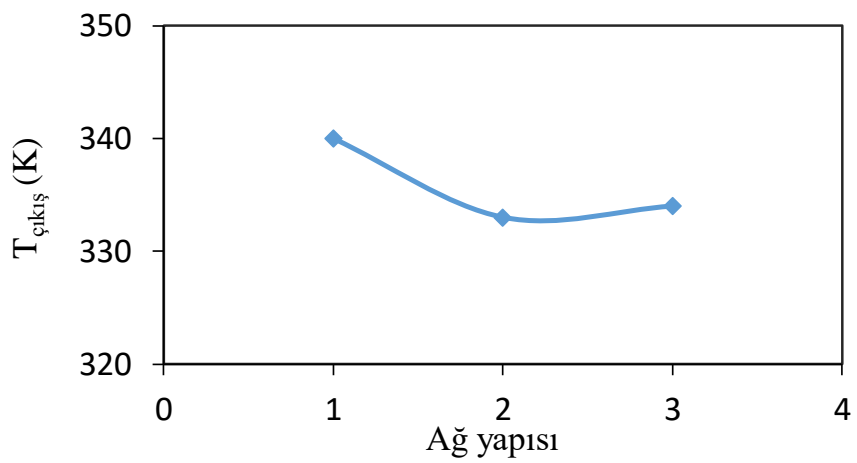

Şekil 15. Disk ve halka şaşırtma levhalı gövde - boru tipi ısı değiştiricisinin ağ yapılarına göre çıkış sıcaklıkları

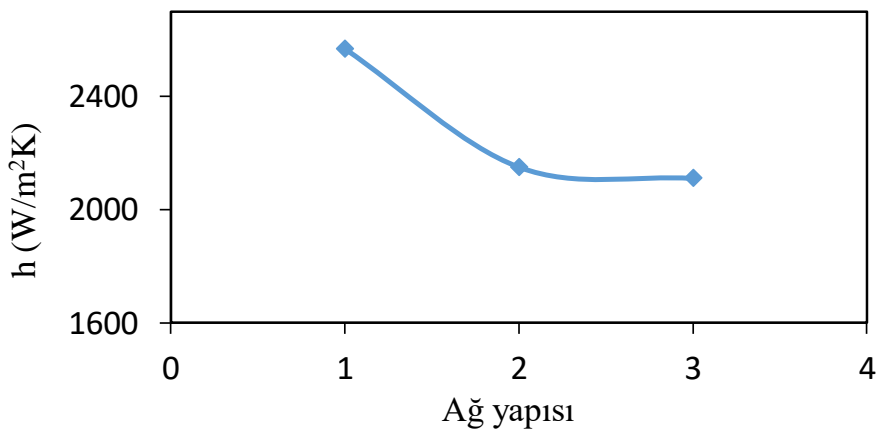

Şekil 16. Disk ve halka şaşırtma levhalı gövde - boru tipi 1sı değiştiricisinin ağ yapılarına göre 1sı taşınım katsayılar1

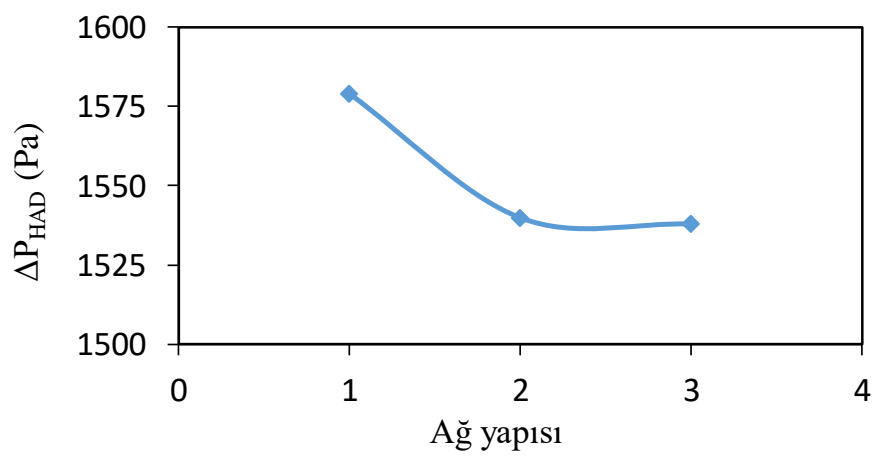

Şekil 17. Disk ve halka şaşırtma levhalı gövde - boru tipi 1sı değiştiricisinin ağ yapılarına göre basınç düşümleri

Şekil 18'de HAD programından alınan raporlara göre; disk ve halka şaşırtma levhalı gövde boru tipi 1sı değiştiricisinin hız akım çizgileri ve sıcaklık dağılımları verilmiştir. 


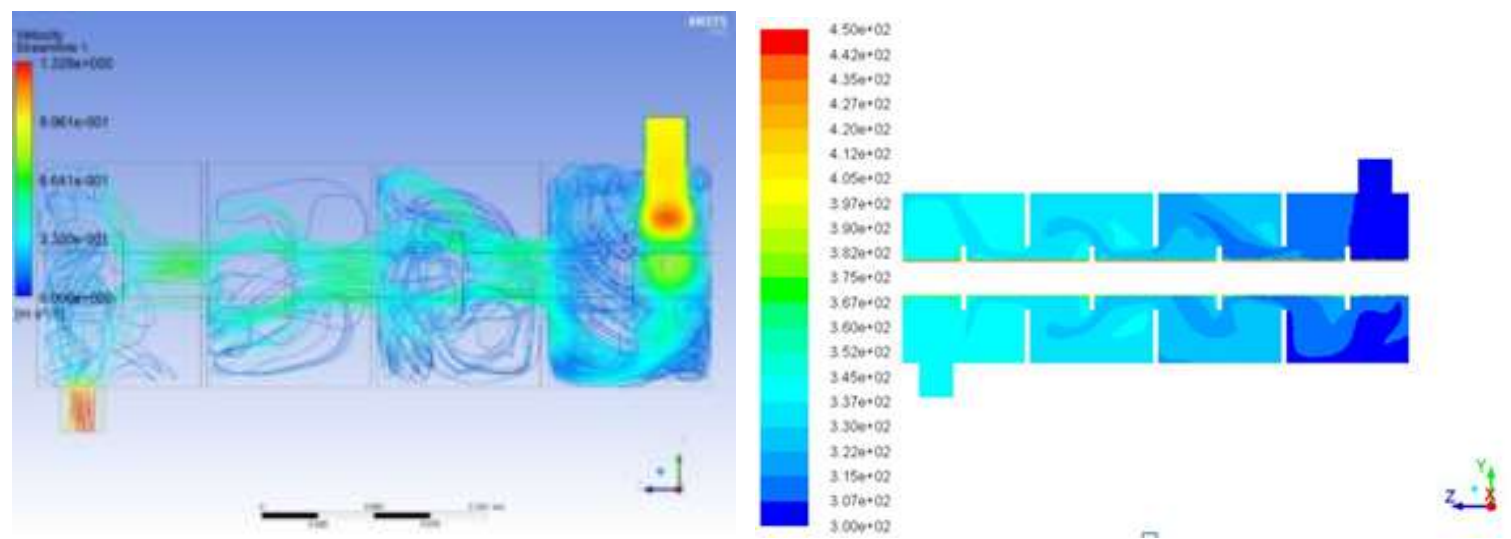

Şekil 18. Disk ve halka şaşırtma levhalı gövde - boru tipi ısı değiştiricisinin hız akım çizgileri ve sıcaklık dağılımı

Tablo 7'de farklı tiplerdeki şaşırtma levhalarının akışa etkileri incelenmiş olup şaşırtma levha tiplerinin önemi belirlenmiştir. Sırasıyla Şekil 19, Şekil 20, Şekil 21'de tek parçalı, disk ve halka biçimindeki şaşırtma levhası kullanılarak oluşturulan gövde - boru tipi 1sı değiştiricilerinin farklı hız değerlerine göre çıkış sıcaklıkları, 1sı taşınım katsayısı, basınç düşüm değişimleri verilmiştir. Şekil 19' da tek parçalı şaşırtma levhalı ve disk halka şaşırtma levhalı gövde - boru tip ısı değiştiricisinde hızın artmasıyla çıkış sıcaklığı azalmıştır. Şekil 20’de hızın artmasıyla 1sı taşınım katsayısı artmıştır. Şekil 21 'de hızın artmasıyla basınç düşümü artmıştır.

Tablo 7. Farklı tip şaşırtma levhalarına göre HAD sonuçları

\begin{tabular}{ccccc}
\hline $\begin{array}{c}\text { Şaşırtma Levha } \\
\text { Tipi }\end{array}$ & $\begin{array}{c}\text { Hiz } \\
(\mathbf{m} / \mathbf{s})\end{array}$ & $\begin{array}{c}\mathbf{T}_{\mathbf{c 2}, \mathbf{H A D}} \\
\mathbf{( K )}\end{array}$ & $\begin{array}{c}\mathbf{h}_{\text {HAD }} \\
\left(\mathbf{W} / \mathbf{m}^{\mathbf{2}} \mathbf{K}\right)\end{array}$ & $\begin{array}{c}\Delta \mathbf{P}_{\text {HAD }} \\
(\mathbf{P a})\end{array}$ \\
\hline Tek Parçalı & 0.3 & 355 & 1204 & 147 \\
Tek Parçalı & 0.5 & 341 & 1571 & 398 \\
Tek Parçalı & 1.0 & 330 & 2267 & 1578 \\
Tek Parçalı & 1.5 & 333 & 2841 & 3482 \\
Disk ve Halka & 0.3 & 355 & 1042 & 147 \\
Disk ve Halka & 0.5 & 342 & 1324 & 400 \\
Disk ve Halka & 1.0 & 334 & 2111 & 1538 \\
Disk ve Halka & 1.5 & 332 & 3038 & 3405 \\
\hline
\end{tabular}

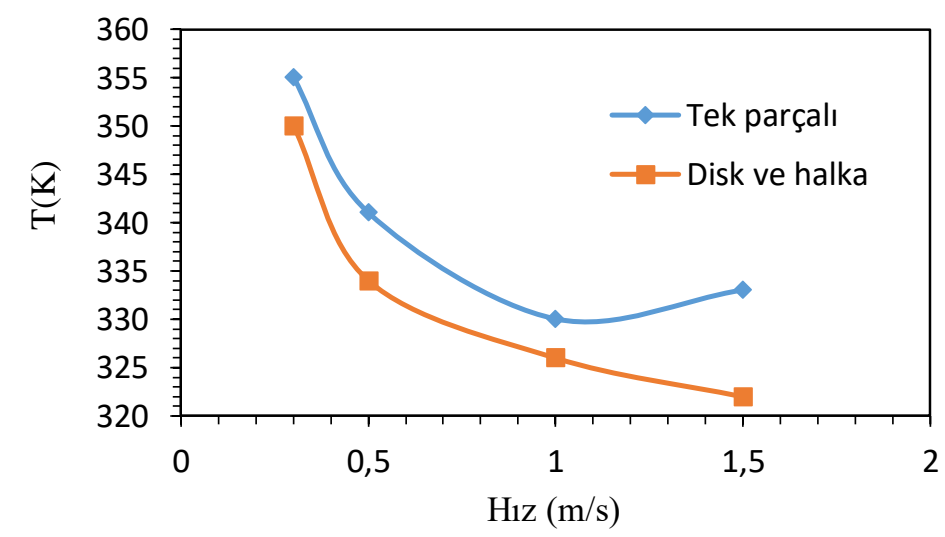

Şekil 19. Şaşırtma levhası tiplerine ve hızlarına göre 1sı çıkış sıcaklıkları 


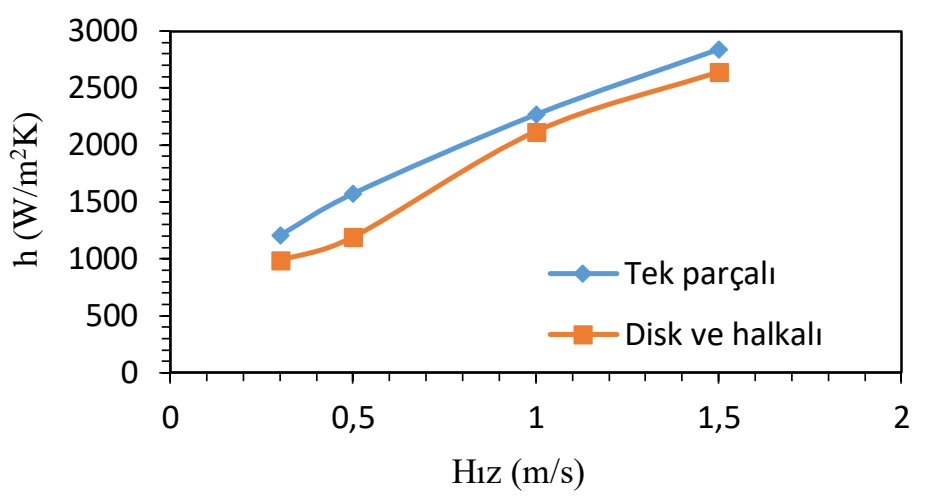

Şekil 20. Şaşırtma levhası tiplerine ve hızlarına göre 1sı taşınım katsayıları

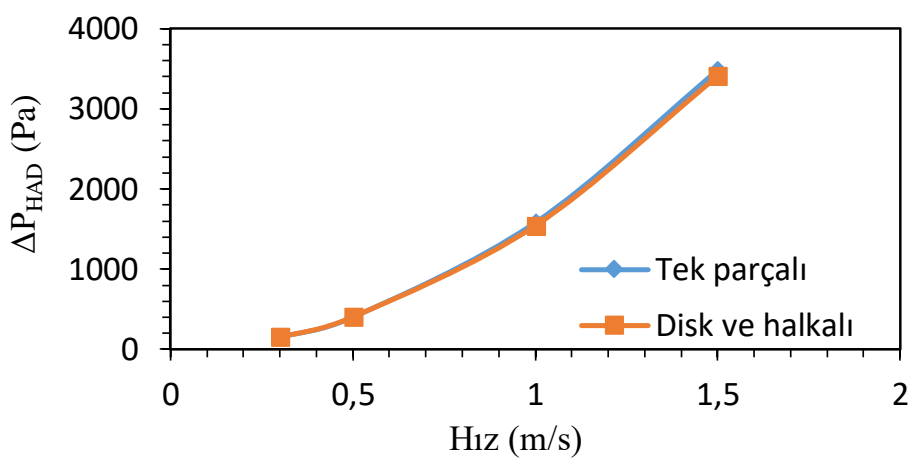

Şekil 21. Şaşırtma levhası tiplerine ve hızlarına göre basınç düşümleri

\section{Sonuçlar ve Öneriler}

Is1 değiştiricilerinde; şaşırtma levhası eklenerek türbülans oluşturulması sağlanmaktadır. Bunun sonucunda, 1sı transferinin arttı̆̆ görülmüştür. Bu çalışmada tek parçalı, disk ve halka şeklindeki şaşırtma levhası kullanılmıştır. Şaşırtma levha tiplerinin 1sı taşınım katsayısı ve basınç düşümüne olan etkisi incelenmiştir. Farklı hız, türbülans modeli, ağ yapısı, iterasyon sayıları alınarak yapılan analizlerin sonuçlarından optimum değerler belirlenmiştir. Akışkanın hız değerinin artması ile basınç düşümü, 1sı taşınım katsayısı ve 1sı transfer miktarı artmıştır, çıkış sıcaklığı azalmıştır. HAD programında yapılan analizlerde model üzerinde uygulanan ağ boyutunun sıkılaşması ile eleman sayısı artmıştır ve eleman sayısının artması analiz süresini de arttırmışıı. İterasyon sayısının artması ile analiz süreleri artmıştır. İterasyon sayısı belirli seviyeye geldikten sonra sonuçların fazla değişmediği görülmüş, yani analizin doğrulandığı belirlenmiştir. HAD programında farklı türbülans modelleri kullanılarak analizler yapılıp türbülans modellerinin analize olan etkileri inceleniştir. $k-\varepsilon$ standart türbülans modeli analiz sonuçlarının analitik sonuçlarla daha iyi eşleştiği görülmüştür. Tek parçalı şaşırtma levhası kullanılan gövde - boru tipi 1sı değiştiricisinde 1sı taşınım katsayısı ve basınç düşümü diğer şaşırtma levhasına göre yüksek bulunmuştur. Basınç düşümünün yüksek olması pompa gücünü ve buna bağlı olarak maliyeti artırmasindan dolayı istenmeyen bir durumdur.

Disk ve halka tipi şaşırtma levhası kullanılan gövde - boru tipi 1sı değiştiricisinde ise basınç düşümü tek parçalı şaşırtma levhasına göre daha düşüktür. Ayrıca, 1Sı taşınım katsayısı ve buna bağlı olarak çıkış sıcaklı̆̆g düşümü tek parçalı şaşırtma levhasına göre daha düşüktür.

Bu çalışmada tek parçalı şaşırtma levhası, disk ve halka şeklindeki şaşırtma levhaları kullanılarak oluşturulan gövde - boru tipi 1sı değiştiricisinin farklı parametrelerdeki değişimleri incelenmiştir. Gelecek çalışmalarda farklı şaşırtma levha tipleri ( 2 parçalı, 3 parçalı, helisel, çiçek şeklinde ) kullanılarak oluşturulan gövde - boru tipi 1sı değiştiricilerin analizleri yapılıp, sonuçları incelenebilir. Oluşturulan model için deneysel çalışmalar yapılıp, doğrulama çalışmaları yapılabilir. Bu çalışmada tek parçalı şaşırtma levhasının HAD analiz sonuçları Kern yöntemi ile karşılaştırılmıştır. Gelecek çalışmalarda HAD analiz sonuçları Bell - Delaware yöntemi kullanılarak çözümler yapılıp karşılaştırılabilir. 


\section{Yazarların Katkısı}

Yazarların makaleye olan katkıları eşit orandadır.

\section{Çıkar Çatışması Beyanı}

Yazarlar arasında herhangi bir çıkar çatışması bulunmamaktadır.

\section{Araştırma ve Yayın Etiği Beyanı}

Yapılan çalışmada araştırma ve yayın etiğine uyulmuştur.

\section{Kaynaklar}

[1] Tinker T. 1951. Shell-Side Characteristics of Shell-and-Tube Heat Exchanger, Parts I, II and III. Proceedings of General Discussion on Heat Transfer. Institute of Mechanical Engineers, London, 97-116.

[2] Anshul J., Sudarshan P. 2015. Comparative Study of Different CFD Models to Evaluate Heat Transfer and Flow Parameters in STHE. International Journal of Engineering Sciences \& Research Technology, 4(6): 536-547.

[3] Zarko S., Gradimir I., Nenad R., Mica V., Velimir S., Goran V. 2001. Design of Shell-and-Tube Heat Exchangers by Usİng CFD Technique - Part One: Thermo-Hydraulic Calculation. Facta Universitatis Series, Mechanical Engineering, 1 (8): 1091-1105.

[4] Ahmet A. 2004. Gövde Borulu Isı Değiştiricilerin Optimizasyonları ve CFD Analizi. Yüksek Lisans Tezi, Sakarya Üniversitesi, Fen Bilimler Enstitüsü, Sakarya.

[5] Aniket S. A., Sivakumar R., Anantharaman N., Vivekenandan M. 2016. CFD Simulation Study of Shell and Tube Heat Exchangers with Different Baffle Segment Configurations. Applied Thermal Engineering, 108: 999-1007.

[6] Koorosh M. 2011. Investigation of the Effects of Baffle Orientation, Baffle Cut and Fluid Viscosity on Shell Side Pressure Drop and Heat Transfer Coefficient in an E-Type Shell and Tube Heat Exchange. Doktora Tezi, Institute for Thermodynamics and Thermal Engineering, University of Stuttgart, Germany.

[7] Rajagapal T.K.R., Srikanth G. 2012. Shell Side Numerical Analysis of a Shell and Tube Heat Exchanger Considering the Effects of Baffle Inclination Angle on Fluid Flow. Thermal Science, 16 (4): 1165-1174.

[8] Anil K.S.R. 2013. Shell and Tube Heat Exchanger Design Using CFD Tools. Bachelor Thesis in Chemical Engineering, National Institute of Technology, Rourkela.

[9] Dinesh B.A., Manaklal H. 2017. CFD Analysis of Shell \& Tube Type Heat Exchanger with Baffles. International Journal for Research Trends and Innovation, 2 (12): 34-37.

[10] Bichkar P., Dandgaval O., Dalvi P., Godase R., Dey T. 2018. Study of Shell and Tube Heat Exchanger with the Effect of Types of Baffles. Procedia Manufacturing, 20: 195-200.

[11] Swapnil S.K., Shivprakash B.B. 2017. Effect of Different types of Baffles on Heat Transfer \& Pressure Drop of Shell and Tube Heat Exchanger: A review. International Journal of Current Engineering and Technology, 7: 358-362.

[12] Halil B., Gökhan S. 2018. Numerical Investigation of the Effects of Different Baffle Types on the Thermal Performance of a Shell and Tube Heat Exchanger. Academic Platform Journal of Engineering and Science, 6 (3): 58-66.

[13] Mukherjee R. 1998. Effectively Design Shell-and-Tube Heat Exchangers. Chemical Engineering Progress, 94: 21-37.

[14] Chalwa C.K, Kadli N. 2013. Study of Variation for Pressure Drop and Temperature Distribution in a Shell and Tube Heat Exchanger in Case of Vertical Baffle. Mechanica Confab, 2 (1): 17-25.

[15] Sandeep G.P., Shashank S.C., Muthalikdesai S.V. 2016. Experimental Investigation on Heat Transfer Performance Comparison for STHXs with Different Baffles. International Engineering Research Journal (IERJ), Special Issue, 256-262. 
[16] Kakac S, Lui H. 2002. Heat Exchangers. Selection, Rating and Thermal Design, Second Edition, Crc Press, Florida. 